\title{
HEALTH-RELATED QUALITY OF LIFE IN SOLDIERS IN CROATIA: RELATIONSHIP WITH COMBAT READINESS AND PSYCHOLOGICAL DIMENSIONS
}

\author{
Davorka Perić1, Darije Plančak², Martina Bulj ${ }^{1}$, Vedrana Tudor ${ }^{3}$, Stjepan Špalj ${ }^{4}$ \\ 'Department of Military Medicine, Croatian Army, Zagreb, Croatia \\ ${ }^{2} S$ chool of Dental Medicine, University of Zagreb, Zagreb, Croatia \\ ${ }^{3} J a d r a n$ Galenski Laboratory, Rijeka, Croatia \\ ${ }^{4}$ School of Medicine, University of Rijeka, Rijeka, Croatia
}

\begin{abstract}
SUMMARY
Health status of soldiers affects their quality of life and combat readiness. The aim of the research was to explore the differences in health-related quality of life (HRQoL) between combat ready und unready soldiers and to what extent are clinically assessed combat readiness and psychological dimensions related to self-reported HRQoL. The study included 402 consecutively selected soldiers aged 21 to 54 (mean age 35.3 \pm 6.0 ) who were classified on the basis of a regular health examination as combat ready $(\mathrm{N}=327)$ and unready $(\mathrm{N}=75)$. HRQoL was assessed using the Short Form-8 Questionnaire and psychological dimensions using the Brief Symptom Inventory. There were no significant differences in physical and mental components of $H R Q 0 L$ between combat ready and unready soldiers. Clinically assessed combat readiness and psychological symptomatic dimensions were weak predictors of $\mathrm{HRQ}$ L. Higher intensity of psychoticism and less years in military service were the only significant predictor of higher physical component of $H R Q L L(p=0.027$ and $p=0.020$, respectively) but accounted for low variability (each $1 \%)$. None variable was a predictor of mental component. In conclusion, clinically assessed combat readiness of soldiers and psychological symptomatic dimensions are poor predictors of HRQoL. HRQoL should be introduced in evaluation of combat readiness.
\end{abstract}

Key words: quality of life, general health, military, combat readiness, psychological dimensions

Address for correspondence: S. Špalj, School of Medicine, University of Rijeka, Braće Branchetta 20, 51000 Rijeka, Croatia. E-mail: stjepan. spalj@medri.uniri.hr

\section{INTRODUCTION}

The quality of life (QoL) of soldiers implies their ability to participate in professional activities required by the military environment in accordance with the intra-psychological abilities and health status (1). Health-related quality of life (HRQoL) may provide insight into the combat readiness of soldiers as it indicates a self-perceived health, functioning and well-being in the physical, mental and social domain (2-4). Only few researches of HRQoL in soldiers have been published so far (5-8). Heretofore, there has been no research that explored the relationship between psychological dimensions and normative assessed combat readiness with the self-perceived HRQoL. Variations in psychological dimensions in soldiers might affect the self-assessment of HRQoL and the reduction of their combat readiness due to stress during a mission. Therefore, adequately rated level of their combat readiness is what the efficiency of the unit and the success of the mission depend on.

Combat readiness is the capability to perform tasks in armed forces in conditions of war and peace and it is periodically systematically examined. This especially applies to candidates for peacekeeping missions who act in different conditions of warfare, different environments with limited support. It is determined by health status, physical, mental and intellectual characteristics (9). Although the armies of ancient Greece and Rome took care about the physical and psychological characteristics of soldiers who composed the legions, it was not until the 18th and the 19th century that the systematic control in conscription of soldiers began to be applied (9). Since the beginning of the 20th century, more attention has been paid to the selection of soldiers due to the fast development of armed forces, and the assessment of military capability became a complex task. The criteria for the assessment of combat readiness vary from army to army and are defined in accordance with the concept of armed forces organization, the level of general and technical culture of the population and the health status. The contemporary methods of warfare require great psychophysical efforts from the soldier, so psychological preparation and good physical fitness are obligatory before military deployment (10-12). Physical exhaustion of soldiers disturbs their mental stability and causes frustrations, nervousness, anxiety, aggressiveness, low motivation, indecision, insecurity, fear, and panic $(10,13)$. Still, dimension of soldiers self-perceived HRQoL is not assessed in evaluation of combat readiness.

The aim of the research was to explore the differences in HRQoL between combat ready and unready soldiers, classified according to medical and fitness evaluation, controlling for age, educational level and military experience. Furthermore, it was aimed to explore to what extent are clinically assessed combat readiness and psychological dimensions related to self-reported HRQoL, controlling for the above-mentioned factors. 
The research hypothesis is that the self-assessed HRQoL is weakly related to the clinically assessed combat readiness of soldiers, but it is considerably under influence of psychological symptomatic dimensions.

\section{MATERIALS AND METHODS}

The study was cross-sectional and a sample consisted of 402 consecutively selected male professional soldiers aged 21 to 54 (mean age 35.3 \pm 6.0 ) during their annual regular health examination at the Department of Military Medicine of Croatian Army in a period from October - November 2010. From the initial sample of 421 soldiers 19 were eliminated due to incomplete or irregularly completed questionnaires. The approval of the Ministry of Defence of the Republic of Croatia (No. 512M2-0301-10/3) was obtained for the research as well as the approval of the Ethics Committee of the University of Zagreb (No. 05-PA-35XVII-11.1.3.2/11). The respondents signed an informed consent for participation in the research.

The research was performed with validated psychometric instruments and clinical medical examination. The recorded sociodemographic parameters included age, educational level, years in military service, and previous participation in international peacekeeping missions.

HRQoL was assessed using the Short Form-8 Health Survey Questionnaire (SF-8) (14), while psychological dimensions were assessed using the Brief Symptom Inventory (BSI) (15). SF-8 measures HRQoL in eight dimensions grouped in two profiles the Physical Component Summary Measure (PCS) - dimensions: perception of general health $(\mathrm{GH})$, physical functioning $(\mathrm{PF})$, rolephysical (RP) and bodily pain (BP), and the Mental Component Summary Measure (MCS) - dimensions: vitality (VT), social functioning (SF), mental health $(\mathrm{MH})$, and role-emotional (RE) (14). Higher scores indicate higher levels of health.

BSI comprises 53 items for measurement of psychopathology that captures multidimensional measure of psychological symptoms in nine dimensions: somatisation, obsession-compulsion, interpersonal sensitivity, depression, anxiety, hostility, phobic anxiety, paranoid ideation, and psychoticism (15). The respondent assesses his intensity of preoccupation or agitation with regard to each of the mentioned 53 problems on the five-level Likert-type scale with limit values of $0=$ "not at all" and $4=$ "to a great extent". BSI showed good reliability in the general US and Croatian population (16). BSI enables calculation of three global psychopathology indices which indicates overall psychological distress level, intensity of symptoms and number of self-reported symptoms: the Global Severity Index (GSI), the Positive Symptom Distress Index (PSDI) and the Positive Symptom Total (PST).

The respondents also assessed their health by using the fivelevel Likert scale with limit values $1=$ "excellent" and $5=$ "poor" as well as how much care they dedicate to keeping themselves healthy on a scale with limit values $1=$ "no care at all" and $5=$ "a lot of care". Psychometric testing was anonymous and selfadministered.

The distribution of respondents into the combat ready and combat unready groups was carried out on the basis of a medical check-up defined by the Regulations on Determining Health Requirements for Military Service in the Croatian Army (17). The medical examinations encompassed determining the status and functional capabilities of all organ systems, organs and sensory organs, central and peripheral nervous system, cognitive capabilities and mental status, and they were performed by specialists of internal medicine, ophthalmology, otorhinolaryngology, physical medicine, occupational medicine, epidemiology, neurology, and psychiatry as well as by a psychologist and intraoral examination without x-rays was performed by dentist. The summary dichotomous rating of the combat readiness (ready or unready) was made by the occupational medicine specialist, based on all examinations performed by all specialists on organ systems and sensory organs.

Mann-Whitney and Chi-square tests were used to test differences in demographic data, military experience, psychological dimensions, and HRQoL between combat ready and unready soldiers in univariate analysis. Multiple logistic regression was used to assess whether parameters of HRQoL can discriminate combat ready and unready soldiers, controlling for age, educational level and military experience. Multiple linear regression analysis was employed to explore the predictive value of clinical and fitness evaluation of combat readiness and psychological dimensions for HRQoL, controlling for the above-mentioned factors. Statistical analysis was performed in commercial software SPSS 10.0 (SPSS Inc., Chicago, Illinois, USA) at significance level $\mathrm{p}<0.05$.

\section{RESULTS}

Out of 402 respondents, $19 \%$ were qualified as combat unready based on the medical check-up. There was no statistically relevant difference in age, years in military service and educational level between the combat ready and the combat unready soldiers, but the combat unready soldiers have statistically considerably less frequently previously participated in peacekeeping missions $(p=0.039)$. The combat ready and the combat unready equally assess their general health and take equal care of it (Table 1). There were no statistically significant differences in physical and most mental components of HRQoL between combat ready and unready soldiers, and role emotional was the only component that was statistically significantly lower in unready soldiers in univariate analysis ( $p=0.038$ ) (Fig. 1). Both groups of respondents gave relatively high marks to all general health components.

Combat unready soldiers had higher intensity of obsessioncompulsion symptoms $(\mathrm{p}=0.029)$, interpersonal sensitivity $(p=0.030)$, depression $(p=0.035)$, and psychoticism $(p=0.034)$ than unready soldiers in univariate analysis (Fig. 1). None of the psychological dimensions was a statistically significant predictor of combat readiness in the multiple logistic regression model (results not shown).

Self-reported health significantly correlated with physical and mental summary measures of SF-8 $(r=-0.399$ and -0.221 ; $\mathrm{p}<0.001$ ), and all particular dimensions of SF-8 (in range from $r=-0.148$ for role emotional to -0.485 for general health). Multiple logistic regression presented in Table 2 was used to assess how well HRQoL can predict combat unreadiness in model with several variables. This approach allowed us to control for the effect of potentially confounding variables age, educational level and military experience. The parameters of physical and mental component of HRQoL are not significant predictors of 
Table 1. The comparison of demographic and military variables as well as of the health self-assessment with regard to combat readiness

\begin{tabular}{|c|c|c|c|c|c|}
\hline & & \multicolumn{4}{|c|}{ Combat readiness } \\
\hline & & $\begin{array}{l}\text { Ready } \\
\mathrm{N}=327\end{array}$ & $\begin{array}{c}\text { Unready } \\
\mathrm{N}=75\end{array}$ & $\begin{array}{c}\text { Total } \\
\mathrm{N}=402\end{array}$ & $\mathrm{p}$ \\
\hline \multirow[t]{2}{*}{ Age } & Mean \pm std. dev. & $35.34 \pm 6.05$ & $34.96 \pm 5.87$ & $35.27 \pm 6.01$ & \multirow[t]{2}{*}{$0.874^{*}$} \\
\hline & Median (quartile range) & $36(33-39)$ & $36(30-40)$ & $36(33-39)$ & \\
\hline \multirow[t]{3}{*}{ Educational level } & Elementary school & $12(3.7 \%)$ & $5(6.7 \%)$ & 17 & \multirow[t]{3}{*}{$0.436^{*}$} \\
\hline & Secondary school & $247(75.5 \%)$ & $57(76 \%)$ & 304 & \\
\hline & College/university & $68(20.8 \%)$ & $13(17.3 \%)$ & 81 & \\
\hline \multirow[t]{2}{*}{ Years in military service } & Mean \pm std. dev. & $13.95 \pm 6.29$ & $13.24 \pm 5.79$ & $13.82 \pm 6.20$ & \multirow[t]{2}{*}{$0.440^{*}$} \\
\hline & Median (quartile range) & $15(10-18)$ & $15(6-18)$ & $15(10-18)$ & \\
\hline \multirow{2}{*}{$\begin{array}{l}\text { Experience in international } \\
\text { military missions }\end{array}$} & No & $131(40.1 \%)$ & $40(53.3 \%)$ & 171 & \multirow[t]{2}{*}{$0.039^{* *}$} \\
\hline & Yes & $196(59.9 \%)$ & $35(46.7 \%)$ & 231 & \\
\hline \multirow[t]{2}{*}{ Self-assessed health status } & Mean \pm std. dev. & $1.76 \pm 0.61$ & $1.84 \pm 0.66$ & $1.78 \pm 0.62$ & \multirow[t]{2}{*}{$0.341^{*}$} \\
\hline & Median (quartile range) & $2(1-2)$ & $2(1-2)$ & $2(1-2)$ & \\
\hline \multirow[t]{2}{*}{ Self-assessed health concern } & Mean \pm std. dev. & $3.63 \pm 0.70$ & $3.56 \pm 0.74$ & $3.62 \pm 0.71$ & \multirow[t]{2}{*}{$0.421^{*}$} \\
\hline & Median (quartile range) & $4(3-4)$ & $4(3-4)$ & $4(3-4)$ & \\
\hline
\end{tabular}

${ }^{*}$ Mann-Whitney test, ${ }^{* *}$ Chi square test

Table 2. Multiple logistic regression model for the prediction of combat unreadiness

\begin{tabular}{|c|c|c|c|c|c|c|}
\hline $\begin{array}{l}\text { Dependent } \\
\text { variable }\end{array}$ & Predictor & B & Std. error & $p$ & Odds ratio & $\begin{array}{l}95 \% \text { confidence } \\
\text { interval }\end{array}$ \\
\hline \multirow{8}{*}{$\begin{array}{l}\text { Combat } \\
\text { unreadiness }\end{array}$} & Constant & 1.241 & 2.008 & 0.537 & & \\
\hline & Age & 0.04 & 0.047 & 0.357 & 1.044 & $0.952-1.145$ \\
\hline & Years in military service & -0.05 & 0.046 & 0.261 & 0.950 & $0.868-1.039$ \\
\hline & $\begin{array}{l}\text { No experience in international } \\
\text { military missions }\end{array}$ & 0.541 & 0.267 & 0.042 & 1.719 & $1.019-2.899$ \\
\hline & $\begin{array}{l}\text { Secondary vs. elementary } \\
\text { education }\end{array}$ & -0.626 & 0.571 & 0.273 & 0.535 & $0.175-1.637$ \\
\hline & Higher vs. elementary education & -0.926 & 0.633 & 0.144 & 0.396 & $0.114-1.371$ \\
\hline & Physical component HRQoL & -0.03 & 0.025 & 0.224 & 0.970 & $0.932-1.019$ \\
\hline & Mental component HRQoL & -0.03 & 0.026 & 0.320 & 0.974 & $0.925-1.026$ \\
\hline
\end{tabular}
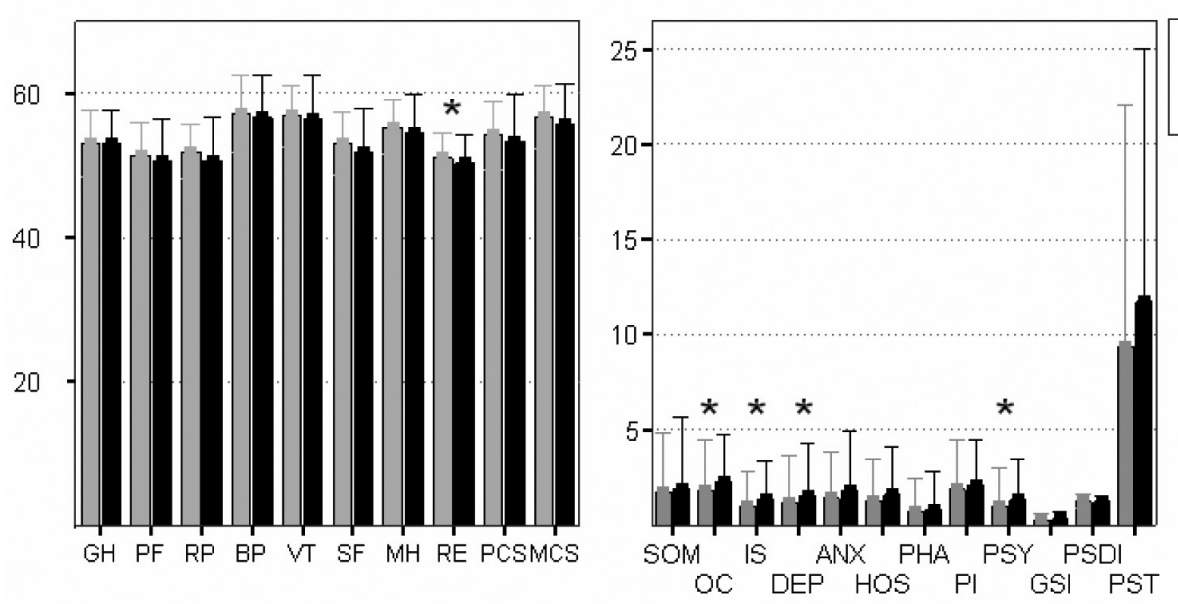

Fig. 1. Comparison of HRQoL and psychological dimensions between combat ready and unready soldiers. 
Table 3. Multiple linear regression model for the prediction of physical component of HRQoL assessed by SF-8

\begin{tabular}{|c|c|c|c|c|c|c|c|}
\hline \multirow{2}{*}{ Predictors } & \multirow{2}{*}{ B } & \multirow{2}{*}{ Std. error } & \multirow{2}{*}{$\beta$} & \multirow{2}{*}{$p$} & \multicolumn{3}{|c|}{ Correlations } \\
\hline & & & & & Zero-order & Partial & Semi partial \\
\hline Constant & 55.249 & 2.437 & & $<0.001$ & & & \\
\hline Chronological age & 0.128 & 0.088 & 0.153 & 0.149 & -0.068 & 0.073 & 0.070 \\
\hline Years in military service & -0.201 & 0.086 & -0.248 & 0.020 & -0.108 & -0.118 & -0.113 \\
\hline $\begin{array}{l}\text { Experience in international military } \\
\text { missions ( } 1=n o, 2=y e s)\end{array}$ & -0.632 & 0.515 & -0.062 & 0.220 & -0.057 & -0.062 & -0.060 \\
\hline Combat readiness & -0.960 & 0.636 & -0.074 & 0.132 & -0.064 & -0.076 & -0.073 \\
\hline Somatisation & -0.082 & 0.154 & -0.052 & 0.596 & -0.169 & -0.027 & -0.026 \\
\hline Obsession-compulsion & -0.340 & 0.206 & -0.178 & 0.100 & -0.191 & -0.084 & -0.080 \\
\hline Interpersonal sensitivity & 0.362 & 0.264 & 0.137 & 0.172 & -0.118 & 0.069 & 0.066 \\
\hline Depression & 0.213 & 0.205 & 0.108 & 0.299 & -0.136 & 0.053 & 0.050 \\
\hline Anxiety & -0.396 & 0.278 & -0.201 & 0.155 & -0.186 & -0.072 & -0.069 \\
\hline Hostility & -0.162 & 0.201 & -0.074 & 0.421 & -0.176 & -0.041 & -0.039 \\
\hline Phobic anxiety & -0.220 & 0.297 & -0.079 & 0.460 & -0.165 & -0.038 & -0.036 \\
\hline Paranoid ideation & -0.181 & 0.166 & -0.092 & 0.275 & -0.137 & -0.055 & -0.053 \\
\hline Psychoticism & 0.573 & 0.258 & 0.232 & 0.027 & -0.110 & 0.112 & 0.108 \\
\hline
\end{tabular}

$R=0.295, R 2=0.087, F=2.853, p=0.001, B-$ unstandardized coefficient, $\beta$ - standardized coefficient

combat readiness, and only absence of previous involvement in international peacekeeping military missions is significant predictor producing 1.7 times higher odds for combat unreadiness $(\mathrm{p}=0.042)($ Table 2$)$.

It can be seen from zero-order correlations in Table 3 that physical component of HRQoL significantly correlates with several psychological dimensions in univariate analysis, but the correlation is weak and negative in range from -0.110 for psychoticism to -0.191 for obsession-compulsion. Higher HRQoL was associated with lower intensity of psychological dimensions. The highest independent power in prediction of physical component of HRQoL has obsessive compulsion which accounted for $3.6 \%$ of variability, but in multivariate model the psychological symptomatic dimensions were mainly not significant predictors of HRQoL. Similarly, in multiple logistic regression, the approach of controlling for the effect of potentially confounding variables age, military experience and combat readiness in assessing how well psychological dimensions can predict HRQoL was used in multiple linear regressions presented in Tables 3 and 4. Higher intensity of psychoticism and less years in military service, controlling for all other variables, were the only significant predictor of better physical component of HRQoL ( $\mathrm{p}=0.027$ and $\mathrm{p}=0.020$, respectively), but they accounted for low variability (each $1 \%$ ). Whole model accounted for $8.7 \%$ of variability in physical component HRQoL ( $\mathrm{p}=0.001$ ) leaving a large portion of variability unexplained.

Zero-order correlations in Table 4 demonstrate that mental component of HRQoL significantly correlates in univariate analysis with general psychological dimensions but correlation is week linear negative in range from -0.32 for hostility to -0.412 for anxiety. In the univariate model the highest predictive value has anxiety accounting for $17 \%$ of variability but in the multivariate model no psychological dimension has statistically significant value in predicting mental component of HRQoL (Table 4).

\section{DISCUSSION}

Military service constitutes a specific working environment where the psychophysical combat readiness is a key working element. Therefore, it is necessary to often simulate psychophysical strain that can be expected in military tasks, and monitor soldiers health and fitness. In wars and military actions the non-war injuries and impaired HRQoL can cause notable loss of manpower, i.e. their inability to perform military tasks.

This study demonstrated absence of relationship between HRQoL and combat readiness defined by health and fitness evaluation. Mental and physical components of HRQoL and self-reported health level can not discriminate clinically classified combat ready and unready soldiers. It confirms that those are two separate categories of health status and that normative evaluation fail to detect soldier's daily functioning related to his own health condition.

Some psychological dimensions (obsession-compulsion symptoms, interpersonal sensitivity, depression, psychoticism, and role-emotional of HRQoL) are more pronounced in combat unready soldiers indicating that those dimensions are to some extent estimated in the existing system of medical combat readiness evaluation. The research carried out among American soldiers and veterans of the Gulf War indicated the highest marks in physical functioning and physical role, and the lowest in general health and vitality (5), which corresponds to this research. Croatian soldiers in both groups gave relatively high marks to all HRQoL components, and much higher marks to mental health and physical pain than Americans. The differences in values may be attributed to cultural differences that may modify the understanding of the quality of life. It is demonstrated that multi-item HRQoL instrument SF-8 significantly correlates with one-item self-reported health status of Croatian soldiers, therefore, they are measuring similar construct. Self-rated overall health appears to be a valid measure of health status among soldiers (18). Moreover, poorer self-rated 
Table 4. Multiple regression model for the prediction of mental component of HRQoL assessed using SF-8

\begin{tabular}{|c|c|c|c|c|c|c|c|}
\hline \multirow{2}{*}{ Predictors } & \multirow{2}{*}{ B } & \multirow{2}{*}{ Std. error } & \multirow{2}{*}{$\beta$} & \multirow{2}{*}{$p$} & \multicolumn{3}{|c|}{ Correlations } \\
\hline & & & & & Zero-order & Partial & Semi partial \\
\hline Constant & 56.979 & 2.079 & & $<0.001$ & & & \\
\hline Chronological age & 0.050 & 0.075 & 0.066 & 0.509 & 0.013 & 0.034 & 0.030 \\
\hline Years in military service & -0.060 & 0.074 & -0.081 & 0.413 & -0.007 & -0.042 & -0.037 \\
\hline $\begin{array}{l}\text { Experience in international military } \\
\text { missions (1=no, } 2=y e s)\end{array}$ & 0.323 & 0.439 & 0.035 & 0.463 & 0.059 & 0.037 & 0.033 \\
\hline Combat readiness & -0.742 & 0.542 & -0.063 & 0.172 & -0.077 & -0.069 & -0.062 \\
\hline Somatisation & -0.205 & 0.131 & -0.145 & 0.119 & -0.396 & -0.079 & -0.071 \\
\hline Obsession-compulsion & 0.216 & 0.176 & 0.124 & 0.220 & -0.338 & 0.062 & 0.056 \\
\hline Interpersonal sensitivity & -0.109 & 0.225 & -0.045 & 0.630 & -0.377 & -0.024 & -0.022 \\
\hline Depression & -0.151 & 0.175 & -0.084 & 0.389 & -0.379 & -0.044 & -0.039 \\
\hline Anxiety & -0.330 & 0.237 & -0.184 & 0.165 & -0.412 & -0.070 & -0.063 \\
\hline Hostility & 0.107 & 0.172 & 0.054 & 0.532 & -0.320 & 0.032 & 0.028 \\
\hline Phobic anxiety & -0.452 & 0.253 & -0.179 & 0.076 & -0.397 & -0.090 & -0.081 \\
\hline Paranoid ideation & -0.172 & 0.142 & -0.096 & 0.226 & -0.334 & -0.061 & -0.055 \\
\hline Psychoticism & 0.225 & 0.220 & 0.100 & 0.307 & -0.354 & 0.052 & 0.047 \\
\hline
\end{tabular}

$\mathrm{R}=0.446, \mathrm{R} 2=0.199, \mathrm{~F}=9.324, \mathrm{p}<0.001, \mathrm{~B}-$ unstandardized coefficient, $\beta$ - standardized coefficient

health is a significant predictor of longer sick-leave duration (19). Although in the univariate analyses the combat unready soldiers had a statistically higher impact of limitations on everyday activities due to emotional troubles as well as higher intensities of some psychological dimension than the combat ready soldiers, none of the specific psychological dimensions was a significant predictor of soldier combat readiness in multivariate analyses.

The biopsychosocial model of health assumes that diseases are under the influence of not only the basic pathology, but also the individual's perception, personality traits and stress (20). It seems that a current medical condition or disease contributes to the explanation of $12-24 \%$ in the variability of HRQoL (21). Additional cofactors such as socio-demographic, physiological and therapeutic characteristics as well as the duration and intensity of disease must be taken into consideration as they may contribute to the explanation of up to $40 \%$ of $\operatorname{HRQoL}(22,23)$.

According to our study variations in psychological traits do not highly influence self-reported HRQoL of soldiers. With the rise in HRQoL the psychological symptomatic dimensions tend to decrease, and psychoticism is the only psychological dimension which, along with the control of other factors in the multivariate model has statistically significant value in the prediction of the physical component of HRQoL. However, it explains only $1 \%$ of the variability. In the multivariate model, the higher intensity of psychoticism is in connection with a higher mark of the HRQoL physical component. Psychoticism is characterised by emotional coldness, egocentrism, inability of empathy, thoughtlessness, rashness and impulsiveness (24). There are standards for certain military professions where a slightly more pronounced psychoticism may even be desirable in commanding positions.

As expected, mental component of HRQoL has a stronger correlation with general psychological dimensions than the physical component, and with the rise in mental component of HRQoL the psychological symptomatic dimensions decrease. Anxiety has the highest individual correlation in the univariate model with the mental component. It is a condition characterised by a feeling of inner angst, agitation, intimidation, and the fear that something terrible is going to happen along with psychomotor tension and inner restlessness (25). It is a result of accumulated stress in life, and an anxious person is constantly in a state of preparedness. Nevertheless, the predictive value of psychological symptomatology is surprisingly low in the explanation of the mental component of the HRQoL, especially because in the multivariate model none of the psychological components presents a significant predictor. Richardson et al. determined that the intensity of depression has a significant predictive role in the assessment of the mental and physical components of HRQoL in war veterans with posttraumatic stress disorder (PTSD) (6). PTSD may affect the quality of life and impair the psychosocial functioning and general well-being (26).

The present study demonstrated that current medical and fitness evaluation in the Croatian Army fail to assess HRQoL. Even with the control of variations in psychological dimensions and demographic factors in addition to clinically assessed combat readiness good prediction of HRQoL can not be accomplished. Epidemiological studies indicate increased symptomatology in soldiers who participated in war events, such as those in the Gulf War, and the impact of war on HRQoL (5, 27-29). Modifying factors such as smoking, combat readiness, morbidity in physical and mental health were independent risk factors for lower HRQoL after the departure to a war mission (5). In our research the participation in war missions was not a significant predictor of lower HRQoL, but shorter years in military service were a significant predictor of better physical component of HRQoL, while the age of the soldier was not. This indicates that the military service with its requirement of constant physical fitness probably increases tiredness in soldiers by lowering their self-assessed health level. It correspondents with the previous finding that active duty soldiers are five times more likely to report active limitations and pain and two times more likely to report not enough rest days (on 
a basis of 14+ days duration) than non-military population (8). None of the psychological pre-war morbidity factors in American soldiers was a predictor of the physical component of HRQoL after the Gulf War. However, PTSD and depression were significant pre-war morbidity factors of risk for the after-war lower mental component of HRQoL (5). Moderate combat readiness in comparison with low combat readiness increases the quality of life's physical component by 2.5 scalar points, high readiness in relation to moderate readiness increases the physical component by 4.9 scalar points and the mental component of HRQoL by 3.1 points. General health and vitality were what made the most significant difference between the soldiers who participated in a war from those who did not, followed by the components of physical pain and mental health, while physical and emotional functioning and related roles had the lowest impact (5). The data indicate the importance of HRQoL assessment before going to war and peacekeeping missions.

According to this study the relationship between self-perceived HRQoL and clinically assessed combat readiness is weak with poor influence of psychological dimensions. Therefore, the HRQoL instruments can be valuable tools in evaluation of combat readiness in addition to medical and fitness examination. By introducing a multidimensional approach this would give a biopsychosocial perspective of combat readiness. The HRQoL instruments can be used for identification of soldiers who, although classified as combat ready according to medical and fitness evaluation, have a higher chance of reporting difficulties in performing military tasks due to self-perceived impairment of HRQoL after deployment. It would reduce the loss of manpower and increase the likelihood for efficient performance of military missions.

\section{CONCLUSION}

HRQoL can not discriminate combat ready und unready soldiers, classified according to medical and fitness evaluation. Clinically assessed combat readiness of soldiers and psychological symptomatic dimensions are poor predictors of HRQoL. HRQoL should be introduced as an additional instrument in evaluation of combat readiness.

\section{Conflict of Interest}

None declared

\section{REFERENCES}

1. Dedić G. The soldier's quality of life during the years of military service. Vojnosanit Pregl. 2003 May-Jun;60(3):305-14. (In Serbian.)

2. Brown M, Gordon WA. Quality of life as a construct in health and disability research. Mt Sinai J Med. 1999 May;66(3):160-9.

3. Rapley M. Quality of life research: a critical introduction. London: Sage; 2003.

4. Raphael D, Renwick R, Brown I, Rootman I. Quality of life indicators and health: current status and emerging conceptions. Soc Indic Res. 1996;39(1):65-88.

5. Voelker MD, Saag KG, Schwartz DA, Chrischilles E, Clarke WR, Woolson RF, et al. Health-related quality of life in Gulf War era military personnel. Am J Epidemiol. 2002 May 15;155(10):899-907.
6. Richardson JD, Long ME, Pedlar D, Elhai JD. Posttraumatic stress disorder and health-related quality of life among a sample of treatment- and pension-seeking deployed Canadian Forces peacekeeping veterans. Can J Psychiatry. 2008 Sep;53(9):594-600.

7. Proctor SP, Harley R, Wolfe J, Heeren T, White RF. Health-related quality of life in Persian Gulf War Veterans. Mil Med. 2001 Jun;166(6):510-9.

8. Barrett DH, Boehmer TK, Boothe VL, Flanders WD, Barrett DH. Healthrelated quality of life of U.S. military personnel: a population-based study. Mil Med. 2003 Nov;168(11):941-7.

9. Gažević N, editor. Military encyclopedia. 2nd ed. Vol. 9. Beograd: Redakcija Vojne enciklopedije; 1975. (In Serbian.)

10. Figelj D, editor. Military psychology. Vol. 2. Zagreb: Ministry of Defence of Republic of Croatia; 2003. (In Croatian.)

11. Kožulj Nj, Rogalo G, Čurčić D. Manual for physical exercise. Zagreb: Ministry of Defence of Republic of Croatia; 2009. (In Croatian.)

12. Panichkul S, Hatthachote P, Napradit P, Khunphasee A, Nathalang O. Systematic review of physical fitness testing to evaluate the physical combat readiness of Royal Thai Armed Forces. Mil Med. 2007 Dec;172(12):12348 .

13. Pavlina Ž, Komar Z, Knezović Z, Filjak T. Military psychology. Vol. 1. Zagreb: Ministry of Defence of Republic of Croatia; 2000. (In Croatian.)

14. Ware JE, Kosinski M, Dewey JE, Gandek B. How to score and interpret single-item health status measures: a manual for users of the SF-8 Health Survey. Lincoln: Quality Metric; 2001.

15. Derogatis LR. Brief Symptom Inventory (BSI) - administration, scoring and procedures manual. Minneapolis: NCS Pearson; 1993.

16. Stibrić M. Psychometric validation of Derogatis Brief Symptom Inventory (BSI) [dissertation]. Zagreb: University of Zagreb; 2005. (In Croatian.)

17. Rules on determining health and physical fitness for military service. Narodne novine. 2008;(97). (In Croatian.)

18. Haddock CK, Poston WS, Pyle SA, Klesges RC, Vander Weg MW, Peterson A, et al. The validity of self-rated health as a measure of health status among young military personnel: evidence from a cross-sectional survey. Health Qual Life Outcomes. 2006 Aug 29;4:57.

19. Selič P, Petek D, Serec M, Rus Makovec M. Sick leave and its determinants in professional soldiers of the Slovenian Armed Forces. Croat Med J. 2010 Dec;51(6):543-51.

20. Engel GL. The need for a new medical model: a challenge for biomedicine. Science. 1977 Apr 8;196(4286):129-36.

21. Stewart AL, Greenfield S, Hays RD, Wells K, Rogers WH, Berry SD, et al. Functional status and well-being of patients with chronic conditions. Results from the Medical Outcomes Study. JAMA. 1989 Aug 18;262(7):907-13. Erratum in: JAMA 1989 Nov 10;262(18):2542.

22. McGee DL, Liao Y, Cao G, Cooper RS. Self-reported health status and mortality in a multiethnic US cohort. Am J Epidemiol. 1999 Jan $1 ; 149(1): 41-6$.

23. Wachtel T, Piette J, Mor V, Stein M, Fleishman J, Carpenter C. Quality of life in persons with human immunodeficiency virus infection: measurement by the Medical Outcomes Study instrument. Ann Intern Med. 1992 Jan 15;116(2):129-37.

24. Eysenck HJ, Eysenck SBG. Psychoticism as a dimension of personality. London: Hodder and Stoughton; 1976.

25. Lohr JM, Lilienfeld SO, Rosen GM. Anxiety and its treatment: promoting science-based practice. J Anxiety Disord. 2012 Oct;26(7):719-27.

26. Schnurr PP, Lunney CA, Bovin MJ, Marx BP. Posttraumatic stress disorder and quality of life: extension of findings to veterans of the wars in Iraq and Afghanistan. Clin Psychol Rev. 2009 Dec;29(8):727-35.

27. Unwin C, Blatchley N, Coker W, Ferry S, Hotopf M, Hull L, et al. Health of UK servicemen who served in Persian Gulf War. Lancet. 1999 Jan 16;353(9148):169-78.

28. Fukuda K, Nisenbaum R, Stewart G, Thompson WW, Robin L, Washko RM, et al. Chronic multisymptom illness affecting Air Force veterans of the Gulf War. JAMA. 1998 Sep 16;280(11):981-8.

29. The Iowa Persian Gulf Study Group. Self-reported illness and health status among Gulf War veterans. A population-based study. JAMA. 1997 Jan 15;277(3):238-45. 